University of Nebraska - Lincoln

DigitalCommons@University of Nebraska - Lincoln

9-2001

\title{
The Metabolic Basis of Life History Variation: Genetic and Phenotypic Differences in Lipid Reserves among Life History Morphs of the Wing-Polymorphic Cricket, Gryllus firmus
}

Anthony J. Zera

University of Nebraska - Lincoln, azera1@unl.edu

A. Larsen

University of Nebraska - Lincoln

Follow this and additional works at: https://digitalcommons.unl.edu/bioscizera

Part of the Microbiology Commons

Zera, Anthony J. and Larsen, A., "The Metabolic Basis of Life History Variation: Genetic and Phenotypic Differences in Lipid Reserves among Life History Morphs of the Wing-Polymorphic Cricket, Gryllus firmus" (2001). Anthony Zera Publications. 35.

https://digitalcommons.unl.edu/bioscizera/35

This Article is brought to you for free and open access by the Papers in the Biological Sciences at DigitalCommons@University of Nebraska - Lincoln. It has been accepted for inclusion in Anthony Zera Publications by an authorized administrator of DigitalCommons@University of Nebraska - Lincoln. 
Published in Journal of Insect Physiology 47:10 (September 2001), pp. 1147-1160; doi 10.1016/S0022-1910(01)00096-8 Copyright () 2001 Elsevier Science Ltd. Used by permission. http://www.sciencedirect.com/science/journal/00221910

Submitted February 28, 2001; accepted April 20, 2001; published online August 27, 2001.

\title{
The Metabolic Basis of Life History Variation: Genetic and Phenotypic Differences in Lipid Reserves among Life History Morphs of the Wing-Polymorphic Cricket, Gryllus firmus
}

\author{
A. J. Zera and A. Larsen \\ School of Biological Sciences, University of Nebraska-Lincoln, Lincoln, NE 68588, USA \\ Corresponding author - A. J. Zera, azera@unlserve.unl.edu
}

\begin{abstract}
The flight-capable morph of the wing-polymorphic cricket, Gryllus firmus, accumulated a substantially greater quantity of total lipid and triglyceride, compared with the obligately flightless morph, during the first five days of adulthood. Increased lipid accumulation in the flight-capable morph was genetically based, and was produced when ovarian growth is substantially reduced in that morph. Temporal changes in lipid levels suggest that the higher triglyceride reserves in the flight-capable morph fed a high-nutrient diet were produced by elevated lipid biosynthesis. By contrast, on a low-nutrient or high carbohydrate diet, increased lipid levels in the flight-capable morph appeared to result primarily from decreased lipid utilization. Increased biosynthesis or retention of triglyceride (the major flight fuel in Gryllus) by the flight-capable morph may significantly divert nutrients from egg production and hence may be an important physiological cause of its reduced ovarian growth. The obligately flightless morph allocated a greater proportion of total lipid to phospholipid than did the flight-capable morph. No functionally-significant differences in total lipid or triglyceride were produced between morphs during the last nymphal stadium. A second flightless morph, derived from the flight-capable morph by histolysis of flight muscles during adulthood, also had reduced amounts of total lipid and triglyceride but increased ovarian growth compared with the flight capable morph on the standard (high-nutrient) diet. Important qualitative and quantitative aspects of lipid metabolism differ genetically between the flight-capable and flightless morphs of G. firmus and likely contribute importantly to their respective adaptations for flight capability vs. reproduction. This is the first study to document genetically-based differences in energy reserves between morphs of a complex (phase, caste, flight) polymorphism in which morphs also differ genetically in key life history traits.
\end{abstract}

Keywords: triglyceride, phospholipid, energetics, life history, trade-off, wing polymorphism, Gryllus, crickets

\section{Introduction}

The functional causes of life history evolution have been a central focus of life history research for over six decades (Fisher, 1930; Pianka, 1981; Towsend and Calow, 1981; Service, 1987; Mole and Zera, 1993; Djawdan et al., 1996; Zera et al., 1998; Zera and Harshman, 2001). At issue are the proximate physiological mechanisms that have been altered by natural selection to produce modified life history traits (e.g. increased early reproduction) and trade-offs between traits (e.g. the coupling of decreased longevity with increased early reproduction). During the past decade, an increasing number of stud- ies have begun to focus on the energetic basis of genetically-determined variation in life history traits within species ( Service, 1987; Djawdan et al., 1996; Harshman and Schmid, 1998; Harshman and Hoffmann, 2000). Yet only a limited amount of information exists on this topic (Zera and Harshman, 2001), with nearly all studies having been conducted on Drosophila melanogaster.

The present study is part of a series whose overall goal is to identify, in detail, the physiological, biochemical and molecular causes of genetically-based life history variation and trade-offs in the wing polymorphic cricket, Gryllus firmus. G. firmus exists in natural populations as three discrete morphs that differ dramatically 
in life history traits. One morph has fully developed wings and flight muscles and is capable of flight [termed 'LW(f)']. A second morph never fully develops wings and flight muscles and is incapable of flight [termed 'SW']. Finally, a second flightless morph is derived from the $\mathrm{LW}(\mathrm{f})$ morph by histolysis (degeneration) of flight muscles during adulthood, when ovarian growth commences [termed 'LW(h)']. Importantly, ovarian growth during the first week of adulthood is substantially faster (i.e. $100-400 \%$ ) in each of the flightless morphs relative to the flight capable morph (Zera et al., 1997, 1998; Zera and Brink, 2000; Zera and Cisper, 2001; Zera and Bottsford, 2001). Thus, resources devoted to the growth and maintenance of flight capability (i.e. somatic growth and maintenance), may reduce the amount of resources available for early reproduction. Importantly, the LW(f) and SW morphs differ genetically from each other in both flight capability (size of wings and flight muscles) and ovarian growth ( Zera and Cisper, 2001; Zera and Bottsford, 2001).

Lipid is the major flight fuel of many insects, including Gryllus, and is often stored in large quantities in adults (Beenakkers, 1983; Candy, 1989; Zera et al., 1999). We previously hypothesized that the necessity of accumulating large quantities of lipid for flight might be an important energetic cost of flight capability that reduces nutrients available for ovarian growth in the $L W(f)$ morph ( Mole and Zera, 1993; Zera et al., 1994, 1998; Zera and Denno, 1997). Direct quantification of energy reserves showed that the LW morph of an unselected stock of G. firmus had greater lipid and triglyceride reserves than the SW morph (Zera et al., 1994), while endocrine manipulation of $G$. assimilis indicated a potential JH-mediated trade-off between ovarian growth and triglyceride accumulation (Zera et al., 1998). However, studies of Zera et al. $(1994,1998)$ had several important limitations which prompted us to undertake the present study. First, comparisons in G. firmus were only made between morphs that differ in wing length (LW vs. SW); long-winged morphs that differ in flight muscles, [LW(f) and LW(h)] were not distinguished. Subsequent studies have shown that the failure to distinguish between these two types of LW morphs, which differ in both flight capability and fecundity during the first week of adulthood, can lead to a substantial underestimate of both the energetic cost of flight capability and the gain in reproductive output due to the evolution of flightlessness (Zera et al., 1997). In addition, the studies of Zera et al. $(1994,1998)$ focused exclusively on phenotypic differences in energy reserves between morphs. Information on the genetic component of these phenotypic differences, which is especially important in evolutionary analyses ( Rose et al., 1996; Zera and Harshman, 2001), was not obtained. Finally, the studies of Zera et al. $(1994,1998)$ were conducted exclusively on adults fed a single high nutrient diet $(100 \%$ diet, see Section 2). The extent to which results obtained in those studies could be generalized to other diets or to the nymphal stage was unknown.

The present study was designed to overcome these limitations by measuring energy reserves in artificially selected lines of G. firmus in which the flight-capable $\mathrm{LW}(\mathrm{f})$ and the flightless SW morphs are known to differ genetically. In addition, all three morphs [LW(f), LW(h) and SW] were characterized separately for differences in energy reserves. Finally, studies were undertaken using three diets that differed dramatically in nutrient content and were conducted on juveniles as well as adults.

\section{Materials and methods}

\subsection{Backgound on G. firmus: morphs, selected stocks, and rearing conditions}

G. firmus, the sand cricket, occurs in the southeastern United States as a long-winged (LW) morph, some of which are capable of flight, or as a short-winged (SW) morph that is obligatory flightless (Veazy et al., 1976; Zera et al., 1997). Except in a few rare cases, all SW females molt into adults with white, non-functional, underdeveloped flight muscles. All LW females initially have fully-developed, functional (pink) flight muscles at or shortly after the adult molt. Individuals with functional flight muscles are denoted as LW(f). Upon onset of ovarian growth, some $L W(f)$ individuals histolyze their flight muscles thus becoming flightless [denoted LW(h); see below and Zera et al. (1997)].

The G. firmus females used in the present study were taken from lines derived from an artificial selection experiment. The experiment consisted of three blocks (independent selection trials), each of which contained a line selected for the LW morph (L line), a line line selected for the SW morph (S line), and a control (C) line [Figure 1; see Zera and Huang (1999)]. The number following the line type (L or S) designates the block from which it is derived. Only selected (L and S) lines are considered here. All lines were raised under the same environmental conditions (photoperiod, density, temperature). Briefly, crickets were reared at $28^{\circ} \mathrm{C}$ under a 16L:8D photoperiod, at a density of 80 and 40 crickets per 10 gallon aquarium during the penultimate and last stadium, respectively. Crickets were switched from the standard 'dry' diet to the standard 100\% wet diet (same components as the dry diet but made up in $2.5 \%$ aqueous agar; see Table 1 ) during the penultimate stadium. Crickets used for the experiments were checked for molting at $24 \mathrm{~h}$ intervals and equal numbers of newly molted males and females were raised at a density of 4-6 per 1 gallon plastic box or 8-12 per 3gallon plastic box. 


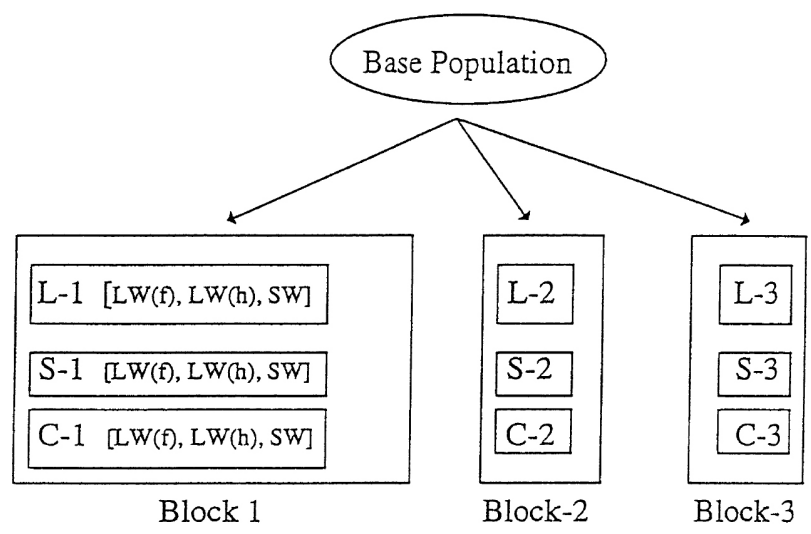

Figure 1. Morphs, lines and blocks used in the artificial selection study on wing morph in G. firmus. L, S, and C denote, respectively, lines selected for the long-winged (LW), or shortwinged (SW) morph, or unselected controls. Block refers to a replicate selection trial. LW(f) denotes a long-winged morph with large functional flight muscles, while LW(h) denotes a long-winged morph with small histolyzed flight muscles. Note that all morphs occur in all lines, but the frequency of the $\mathrm{LW}(\mathrm{f})$ morph is significantly higher in the L lines (0.82-0.77) than in the S lines (0.24-0.05; Zera and Bottsford, 2001; Zera and Cisper, 2001). See Section 2 for additional details.

Table 1. Composition of diets used in the present study. All diets also contained $6 \mathrm{ml}$ of formalin and $6 \mathrm{~g}$ of methyl paraben (mold inhibitor).

\begin{tabular}{lrrr}
\hline Components & Diet & & \\
\cline { 2 - 4 } & $100 \%$ & $25 \%$ & $25 \%$ +sucrose \\
\hline Water (ml) & 3200 & 3200 & 3200 \\
Agar $(\mathrm{g})$ & 80 & 80 & 80 \\
Casein (g) & 104 & 26 & 26 \\
Wheat bran (g) & 288 & 72 & 72 \\
Yeast (g) & 64 & 16 & 16 \\
Wheat germ (g) & 272 & 68 & 68 \\
Cellulose (g) & 0 & 546 & 182 \\
Sucrose (g) & 0 & 0 & 364 \\
\hline
\end{tabular}

No oviposition material was provided so that females would retain all of their eggs which would be included in the whole-cricket lipid extracts. There is virtually no oviposition during the period of adult development studied (first five days of adulthood), even when oviposition material is provided. In contrast to suggestions made by Tanaka (2001), absence of oviposition material has no detectable inhibiting effect on ovarian development in either morph of $G$. firmus during the first week of adulthood under experimental conditions used in our typical trade-off studies (e.g. first week of adulthood with adults reared at $28^{\circ} \mathrm{C}$; see Zera et al., 1997, 1998; Cisper et al., 2000; Zera and Brink, 2000; Zera and Cisper, 2001; Zera and Bottsford, 2001; present study). In the absence of oviposition material, the flightless morph of G. firmus exhibits 2-4 fold greater ovarian growth compared with the flight-capable morph during early adulthood (e.g. Figure 7; also see references mentioned above). Dif- ferences of this magnitude are typical of variations in ovarian growth between morphs of wing-polymorphic species that have been reported for decades (Johnson, 1969; Roff, 1986; Zera and Denno, 1997). Experiments conducted by Tanaka (2001), which purportedly indicate that the lack of oviposition material inhibits ovarian growth in Gryllus, were: (1) conducted at a higher temperature $\left(30^{\circ}\right)$ than any of our studies (all performed at $28^{\circ} \mathrm{C}$ ); and (2) were performed on a cricket (Modicogryllus) that has a faster rate of ovarian development than Gryllus. Both of these factors almost certainly caused the faster ovarian development observed by Tanaka (2001) compared with that observed in our typical trade-off studies on G. firmus.

Additional information on the origin of the lines of G. firmus, and breeding can be found in Zera and Huang (1999), Zera and Bottsford (2001), and Zera and Cisper (2001). In the present study, crickets were used during generation nine of selection. During this generation, LW(f) individuals from the L lines and SW individuals from the $\mathrm{S}$ lines differ genetically in the size of wings, flight muscles, and ovaries (Zera and Bottsford, 2001; Zera and Cisper, 2001).

\subsection{Measurements of energy reserves}

On the day of collection, crickets were placed in containers with water but without food for $6 \mathrm{~h}$ to clear food from the gut. Adults were weighed and their wing and flight muscle phenotype scored. Flight muscle phenotype of LW adults was determined by removing a small piece of thoracic cuticle and scoring the color of the dorsoventral muscle which is perfectly correlated with flight muscle status (pink= large/functional and WHITE=histolyzed/non-functional; Zera et al., 1997). All SW adults had reduced muscles during all adult stages ( Zera et al., 1997). Crickets were placed individually in tubes with $3.3 \mathrm{ml}$ of chloroform containing $0.05 \%$ BHT (butylated hydroxytoluene; antoxident). The chloroform was flushed with nitrogen and tubes were stored at $-86^{\circ} \mathrm{C}$. Prior to homogenization, $1.7 \mathrm{ml}$ methanol (with BHT) was added, crickets were homogenized, and lipids were extracted as described in Zera et al. (1994). A $600 \mu \mathrm{l}$ aliquot of the chloroform-methanol extract was saved and the remainder was poured into a weighed piece of aluminum foil and allowed to evaporate overnight. Total lipid was determined by reweighing the foil the next day. Total lipid, triglyceride, and phospholipid were measured on the $600 \mu \mathrm{l}$ saved extract using the vanillin assay (Van Handel, 1985) with triolein as a standard. Total lipid was measured on one aliquot of the extract. A second aliquot $(200 \mu \mathrm{l})$ was brought up to $1 \mathrm{ml}$ by addition of chloroform, $200 \mathrm{mg}$ of silicic acid (60-200 mesh; Sigma Chemical Co.) was added, and the mixture was vortexed for a few seconds. Silicic acid binds all phospholipid, but not other lipid classes in the extract (Van Handel, 1965; see below). Silicic acid plus bound 
phospholipid were removed by centrifugation. Assay of the supernatant measures total lipid minus phospholipid, which is essentially equal to the triglyceride content ( Van Handel, 1985; see below). The difference between the two aliquots quantifies the amount of phospholipid in the extract.

Background experiments documented that silicic acid removes nearly all phospholipid $(91 \pm 3.4 \%$ reduction in phosphatidyl choline; $n=3$ ) from a chloroform-methanol solution while removing very little triglyceride $(3.1 \pm 1.6 \%$ reduction in triolein; $n=3)$. Thin-layer chromatographic analysis of lipid extracts documented that greater than $90 \%$ of total lipid in G. firmus consists of triglyceride and phospholipid (data not shown), as has been documented in other insects such as mosquitoes (Van Handel, 1985). Thus, the total lipid assay of the extract with phospholipid removed essentially measures triglyceride content. The correlation between total lipid measured gravimetrically (evaporation from foil) vs. the vanillin assay was high $(r=0.92, n=434, P<0.000)$, indicating that the vanillan assay accurately measures lipid content of G. firmus. Soluble carbohydrate (= water soluble sugars and glycogen) was extracted from the fat-free cricket residue and quantified using the anthrone assay as described previously (Zera et al., 1994). The remaining cricket residue was then freeze dried and weighed.

Similar procedures were used to quantify total lipid and soluble carbohydrate in female G. firmus during the last nymphal stadium. Although the L and S lines differ significantly in morph frequencies, none of the lines was purebreeding (L lines contained $77-82 \%$ LW females, while $S$ lines contained 5-24\% LW females; Zera and Cisper, 2001). There are no external morphological features that can be used to distinguish presumptive LW and SW morphs during the last stadium. Therefore, morphs were distinguished by their activity of hemolymph juvenile hormone esterase (JHE) as described in Zera and Huang (1999). The activity of this enzyme, which is measured on $2 \mu 1$ of hemolymph, exhibits virtually non-overlapping distributions in nascent LW and SW morphs during the mid-last stadium.

\subsection{Experimental design}

\subsubsection{Morphs, diets and ages studied}

The main purpose of the present study was to test the hypothesis that morphs that differ phenotypically and genetically in flight capability (size/functionality of wings and flight muscles) and reproduction (ovarian growth) also differ phenotypically and genetically in lipid and carbohydrate reserves. The main comparison was between the flight-capable LW(f) morph, which has fully-developed wings and fully-developed flight muscles, and the obligately flightless SW morph, which does not fully develop its wings or flight muscles. We also compared reserves between the LW(f) morph and the other flightless morph [LW(h)], and between the two flightless morphs. The purpose of these comparisons was to determine the extent to which lipid metabolism is altered in flightless morphs that are produced by different developmental mechanisms operating during different developmental stages. In these studies $L W(\mathrm{f})$ and $\mathrm{LW}(\mathrm{h})$ females were taken from the L lines, while SW females were taken from the $S$ lines (Zera and Cisper, 2001).

To determine the extent to which differences between morphs in energy reserves were contingent upon diet, comparisons were made between morphs fed one of the three diets during adulthood (Table 2). All nymphs were raised on the standard high-nutrient diet (termed ' $100 \%$ ' diet), which had been used in earlier feeding studies (Mole and Zera, 1993; Zera et al., 1998; Zera and Brink, 2000). All individuals were fed this diet during the penultimate and last nymphal stadia. Starting on the day of adult molt, one group of adults was fed this same diet. A second group of adults was fed a low nutrient diet in which $75 \%$ of the dry mass of the high-nutrient diet had been replaced with non-nutritive cellulose (termed '25\%' diet) - used previously in Zera et al. (1998) and in Zera and Brink (2000). A third group of crickets was fed a high-carbohydrate diet starting on the first day of adulthood. In this diet $67 \%$ of the cellulose of the low nutrient diet was replaced with sucrose (termed ' $25 \%$ + sucrose' or 'high carbohydrate' diet). All diets had the same dry mass and water content. Reserves also were measured on nymphs fed either the $100 \%$ diet or the $25 \%$ + sucrose diet. Because crickets exhibited low survivorship and produced only a small number of $\mathrm{LW}(\mathrm{f})$ adults on the $25 \%$ diet, reserves were not measured on that diet. Energy reserves were compared between morphs on days 5 and 8 of the 13-day last nymphal stadium, on the day of the molt to adulthood, and on days 2 and 5 of adulthood. These days were chosen to determine whether differences between the morphs in energy reserves are produced prior to or during days 3-5 of adulthood, when dramatic differences in ovarian growth first occur between morphs ( Zera et al., 1997; Cisper et al., 2000; Zera and Cisper, 2001).

2.3.2. Analyses of phenotypic and genetic differences in reserves

The existence of phenotypic differences in energy reserves among individual morphs, resulting from the combined effects of variation in genotype and environment, was ascertained by factoral ANCOVA. Morph, day, diet, and block were main effects, and lean dry mass (total dry mass minus total lipid) was the covariate. Lean dry mass rather than total dry mass was the covariate because a large component of total dry mass was due to total lipid, one of the dependent variables analyzed by ANCOVA. In these tests, degrees-of-freedom were based on the number of individuals analyzed. Because 
Table 2. Total lipid and triglyceride content (mg) of LW(f)-selected and SW-selected morphs of G. firmus fed various diets

\begin{tabular}{|c|c|c|c|c|c|}
\hline \multirow[b]{2}{*}{ Diet } & \multirow[b]{2}{*}{ Morph } & \multicolumn{3}{|c|}{ Block } & \multirow{2}{*}{$\begin{array}{r}\text { Paired } \\
t \text {-tests of } \\
\text { means }(2 \mathrm{df})\end{array}$} \\
\hline & & 1 & 2 & 3 & \\
\hline \multicolumn{6}{|c|}{ Total lipid (mg) } \\
\hline \multirow[t]{2}{*}{$100 \%$} & $\mathrm{LW}(\mathrm{f})$ & $\begin{array}{l}22.1 \pm 1.8 \\
(19)^{\mathrm{a}}\end{array}$ & $\begin{array}{l}37.8 \pm 1.6 \\
(24)\end{array}$ & $\begin{array}{l}45.0 \pm 2.6 \\
(11)\end{array}$ & $\begin{aligned} t & =7.63 \\
P & =0.017\end{aligned}$ \\
\hline & SW & $\begin{array}{l}16.8 \pm 1.7 \\
(20)^{*}\end{array}$ & $\begin{array}{l}29.6 \pm 1.7 \\
(20)^{* * *}\end{array}$ & $\begin{array}{l}37.1 \pm 1.8 \\
(19)^{* * *}\end{array}$ & \\
\hline \multirow[t]{2}{*}{$25 \%$} & $\mathrm{LW}(\mathrm{f})$ & $\begin{array}{l}19.1 \pm 1.3 \\
(21)\end{array}$ & $\begin{array}{l}21.8 \pm 1.2 \\
(23)\end{array}$ & $\begin{array}{l}32.6 \pm 1.9 \\
(11)\end{array}$ & $\begin{array}{l}t=4.93 \\
P=0.039\end{array}$ \\
\hline & SW & $\begin{array}{l}16.5 \pm 1.3 \text { n.s. } \\
(19)\end{array}$ & $\begin{array}{l}14.7 \pm 1.9 \\
(13)^{* * *}\end{array}$ & $\begin{array}{l}27.3 \pm 1.5 \\
(17)^{*}\end{array}$ & \\
\hline \multirow[t]{2}{*}{$25 \%+S$} & $\mathrm{LW}(\mathrm{f})$ & $\begin{array}{l}21.8 \pm 1.6 \\
(19)\end{array}$ & $\begin{array}{l}27.8 \pm 1.5 \\
(21)\end{array}$ & $\begin{array}{l}37.7 \pm 1.7 \\
(16)\end{array}$ & $\begin{array}{l}t=6.57 \\
P=0.02\end{array}$ \\
\hline & SW & $\begin{array}{l}14.9 \pm 1.6 \\
(19)^{* * *}\end{array}$ & $\begin{array}{l}23.8 \pm 1.6 \\
\text { (18) n.s. }\end{array}$ & $\begin{array}{l}31.7 \pm 1.6 \\
(20)^{* *}\end{array}$ & \\
\hline \multicolumn{6}{|c|}{ Triglyceride (mg) } \\
\hline \multirow[t]{2}{*}{$100 \%$} & $\mathrm{LW}(\mathrm{f})$ & $\begin{array}{l}18.6 \pm 1.5 \\
(19)\end{array}$ & $\begin{array}{l}27.8 \pm 1.8 \\
(14)\end{array}$ & $\begin{array}{l}42.7 \pm 2.2 \\
(11)\end{array}$ & $\begin{array}{l}t=6.14 \\
P=0.026\end{array}$ \\
\hline & SW & $\begin{array}{l}12.5 \pm 1.5 \\
(20)^{* * *}\end{array}$ & $\begin{array}{l}22.9 \pm 1.7 \\
(15) \text { n.s. }\end{array}$ & $\begin{array}{l}34.2 \pm 1.5 \\
(19)^{*}\end{array}$ & \\
\hline \multirow[t]{2}{*}{$25 \%$} & $\mathrm{LW}(\mathrm{f})$ & $\begin{array}{l}16.7 \pm 1.1 \\
(21)\end{array}$ & $\begin{array}{l}15.2 \pm 1.2 \\
(18)\end{array}$ & $\begin{array}{l}29.4 \pm 1.7 \\
(11)\end{array}$ & $\begin{array}{l}t=16.04 \\
P=0.004\end{array}$ \\
\hline & SW & $\begin{array}{l}12.4 \pm 1.1 \\
(21)^{* *}\end{array}$ & $\begin{array}{l}9.9 \pm 1.8 \\
(9)^{* *}\end{array}$ & $\begin{array}{l}24.3 \pm 1.2 \\
(17)^{* *}\end{array}$ & \\
\hline \multirow[t]{2}{*}{$25 \%+S$} & $\mathrm{LW}(\mathrm{f})$ & $\begin{array}{l}17.7 \pm 1.42 \\
(19)\end{array}$ & $\begin{array}{l}4.2 \pm 1.6 \\
(14)\end{array}$ & $\begin{array}{l}34.7 \pm 1.5 \\
(16)\end{array}$ & $\begin{array}{l}t=8.71 \\
P=0.013\end{array}$ \\
\hline & SW & $\begin{array}{l}10.7 \pm 1.4 \\
(19)^{*}\end{array}$ & $\begin{array}{l}16.6 \pm 1.4 \\
(18)^{* * *}\end{array}$ & $\begin{array}{l}29.6 \pm 1.4 \\
(20)^{* *}\end{array}$ & \\
\hline \multicolumn{6}{|c|}{ Soluble carbohydrate (mg) } \\
\hline \multirow[t]{2}{*}{$100 \%$} & $\mathrm{LW}(\mathrm{f})$ & $\begin{array}{l}0.63 \pm 0.03 \\
(19)\end{array}$ & $\begin{array}{l}0.91 \pm 0.03 \\
(26)\end{array}$ & $\begin{array}{l}0.84 \pm 0.05 \\
(11)\end{array}$ & $\begin{array}{l}t=1.44 \\
P=0.29\end{array}$ \\
\hline & SW & $\begin{array}{l}0.51 \pm 0.03 \\
(20)^{* *}\end{array}$ & $\begin{array}{l}0.75 \pm 0.03 \\
(20)^{* * *}\end{array}$ & $\begin{array}{l}0.87 \pm 0.03 \\
(19) \text { n.s. }\end{array}$ & \\
\hline \multirow[t]{2}{*}{$25 \%$} & $\mathrm{LW}(\mathrm{f})$ & $\begin{array}{l}0.52 \pm 0.02 \\
(21)\end{array}$ & $\begin{array}{l}0.77 \pm 0.02 \\
(26)\end{array}$ & $\begin{array}{l}0.73 \pm 0.03 \\
(11)\end{array}$ & $\begin{array}{l}t=2.30 \\
P=0.14\end{array}$ \\
\hline & SW & $\begin{array}{l}0.49 \pm 0.02 \\
(21) \text { n.s. }\end{array}$ & $\begin{array}{l}0.44 \pm 0.02 \\
(21)^{* * *}\end{array}$ & $\begin{array}{l}0.41 \pm 0.03 \\
(17)^{\star * *}\end{array}$ & \\
\hline \multirow[t]{2}{*}{$25 \%+S$} & $\operatorname{LW}(\mathrm{f})$ & $\begin{array}{l}0.53 \pm 0.03 \\
(19)\end{array}$ & $\begin{array}{l}0.81 \pm 0.03 \\
(23)\end{array}$ & $\begin{array}{l}0.77 \pm 0.03 \\
(16)\end{array}$ & $\begin{array}{l}t=0.31 \\
P=0.70\end{array}$ \\
\hline & SW & $\begin{array}{l}0.62 \pm 0.03 \\
(19)^{*}\end{array}$ & $\begin{array}{l}0.72 \pm 0.03 \\
(21)^{*}\end{array}$ & $\begin{array}{l}0.72 \pm 0.03 \\
(20) \text { n.s. }\end{array}$ & \\
\hline
\end{tabular}

${ }^{a}$ Means $\pm S E M$ (sample size) are adjusted least-squares mean derived from ANCOVA (see Section 2). Values are for data pooled across days 2 and 5 of adulthood (see Figure 2 for means on individual days). Symbols outside parentheses are significance levels of unparied $t$-tests between SW and LW(f) females of the same block and diet: * $=P<$ $0.05, * *=P<0.025, * * *=P<0.005$, n.s. $=$ non-significant $(P>0.05)$. $25 \%+S=25 \%+$ sucrose diet.

we were primarily interested in investigating differences between specific pairs of morphs, three separate ANCOVAs were performed rather than a single overall ANCOVA. One ANCOVA tested for differences in energy reserves between the flight-capable and obligately flightless morphs [LW(f) vs. SW], a second tested for differences between the flight-capable and the flightless morph produced by flight-muscle histolysis [LW(f) vs. $L W(h)]$, while the third tested for differences between the two flightless morphs [LW(h) vs. SW]. Because these were a priori contrasts, significance levels were not adjusted for experiment-wide error. In preliminary analyses, no interactions were observed between block and any other main effect. Hence, block was removed from the subsequent analyses (i.e. data were pooled across blocks).

The main genetic hypothesis tested in the present study was that LW(f)-selected and SW-selected females, that differ genetically in the size of wings, flight muscles, and ovaries (Zera and Bottsford, 2001; Zera and Cisper, 2001), also differ genetically in the concentration of energy reserves. Genetically-based differences in reserves should be manifested as consistent differences between $L W(f)$ females from an L line compared with SW females of the $S$ line of the same block, for each of the three blocks (see Figure 1). This hypothesis was tested in two ways. First, the mean difference in reserves between LW(f)-selected and SW-selected females of the same block was ascertained by a $t$-test, and the consistency of differences between morphs in each of the three blocks was assessed. Second, mean reserves were compared between morphs by paired $t$-tests, as had been done previously for genetic analyses of other physiological traits in G. firmus (Zera and Huang, 1999; Zera and Bottsford, 2001; Zera and Cisper, 2001). Briefly, the difference in the mean value for a particular compound between LW-selected females of an L line and SW-selected females from the $S$ line of the same block was computed. This was repeated for the other two blocks. The mean and standard error of the three differences was then used to compute a $t$-statistic. Note that in these paired $t$ tests, degrees-of-freedom were based on the number of pairs of lines $(=$ blocks) compared $(\mathrm{df}=2)$. When paired $t$-tests were performed on reserves measured on several days of adulthood or on several diets, least-squares means of these data were computed so that the paired $t$ tests were always performed using only one mean from each selected group. This was done to avoid pseudoreplication (inflation of degrees-of-freedom; see Rose et al., 1996 and Zera and Huang, 1999). Means used in these genetic analyses were adjusted least-squares means derived from the ANCOVAs. Genetic analyses of energy reserves could not be compared between $L W(h)$ vs. $\mathrm{LW}(\mathrm{f})$ or SW morphs, because it is unknown whether phenotypic differences between these morphs have any genetic component ( Zera and Cisper, 2001).

\subsection{Correlations}

Phenotypic correlations between various reserves were computed as partial correlations with lean dry 
mass held constant. That is, correlations were calculated on residuals of variables that had been regressed on lean dry mass.

\section{Results}

\subsection{Total and lean dry mass}

On the day of the adult molt, total dry mass of the LW(f) morph was essentially equivalent to, or was slightly greater than, that of the SW morph $\left[F_{(1,55)}=4.1\right.$, $0.045<P<0.050$ ], while morphs did not differ in lean dry mass [lipid-free dry mass; $F_{(1,55)}=2.1, P=0.15$; Figure 2]. On day 5 , morphs were also equivalent in total dry mass when tested over all diets or on each diet sep- arately ( $P>0.15$ in each ANOVA). By contrast, lean dry mass was significantly higher in the SW morph on day 5 over all diets [ANOVA: $F_{(1,155)}=27.5, P<0.005$; Figure $2]$. There was no significant morph $\times$ diet interaction $(P=$ $0.66)$ indicating that the difference between morphs in lean dry mass was not diet specific.

3.2. Phenotypic differences between the flight-capable $L W(f)$ and the obligately flightless $S W$ morphs in energy reserves

Total lipid, triglyceride, phospholipid, and carbohydrate were each measured in more than 250 G. firmus. Values for these chemical components presented in the figures and tables are adjusted least-squares means derived from ANCOVA using lean dry mass as the covari-

\section{Total}
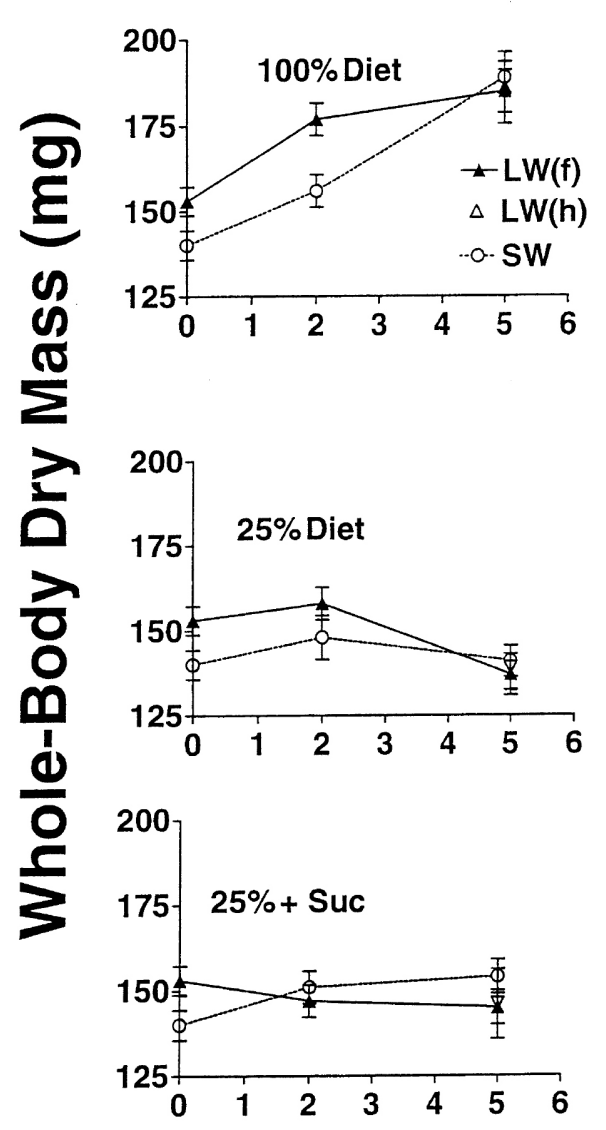

Lean
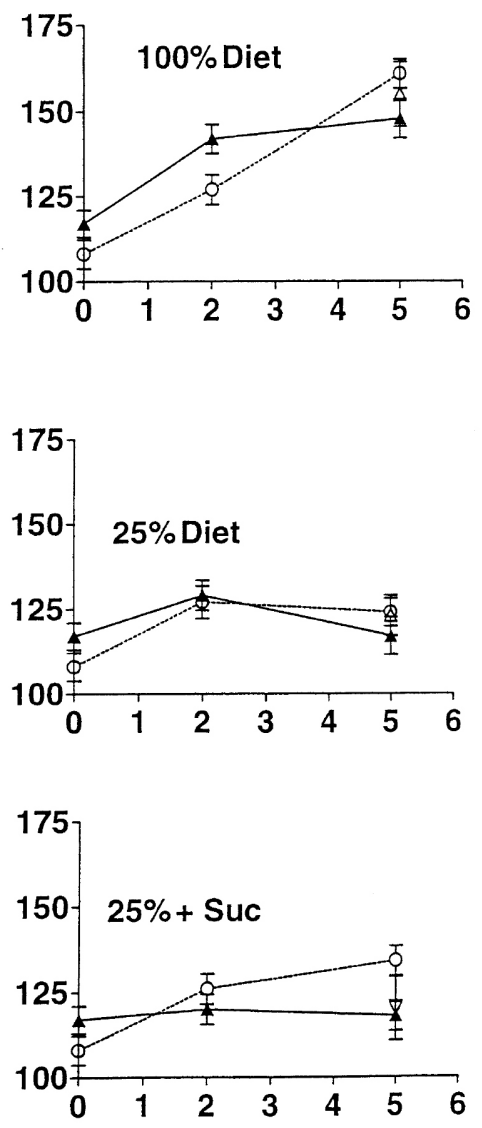

\section{Age (days)}

Figure 2. Mean ( \pm SEM) total dry mass (left panels) and lean dry mass (lipid-free dry mass; right panels) for the three wing- and flight-muscle morphs of G. firmus as a function of adult age and diet. Morph designations are defined in the legend of Figure 1 and diets are defined in Section 2. Data were pooled across the three blocks (independent selection trials). Sample sizes ranged from 23-28 for each morph on each day on each diet. 
ate (i.e. values were adjusted for variation in lean body mass among individual crickets; see Section 2). Adjusted means were very similar to (within $6 \%$ of) mean triglyceride mass unadjusted for body mass.

The flight-capable $L W(f)$ and the flightless SW morphs did not differ significantly in total lipid content on the first day of adulthood $\left[F_{(1,54)}=1.29, P=0.26\right.$; Figure 3]. However, on both day 2 and 5, the LW(f) morph had a significantly higher total lipid content compared with the SW morph, over all diets [day 2: $F_{(1,146)}=20.8$, $P=0.000$; day 5: $\left.F_{(1,148)}=42.3, P=0.000\right]$, and on each diet tested separately [day 2: $100 \%$ diet, $F_{(1,51)}=4.01$, $P=0.05 ; 25 \%$ diet, $F_{(1,41)}=12.19, P=0.001 ; 25 \%+$ sucrose diet: $F_{(1,52)}=6.34, P=0.015$; day 5: $100 \%$ diet: $F_{(1,}$ ${ }_{48)}=24.2, P=0.000 ; 25 \% \operatorname{diet}: F_{(1,51)}=5.79, P<0.025 ; 25 \%$ + sucrose diet: $\left.F_{(1,47)}=11.24, P=0.002\right]$. Total lipid accounted for $18 \%$ [LW(f)] or 15\% (SW) of total dry mass over all days, blocks and diets.

Triglyceride accounted for approximately 83\% [LW(f)] or $80 \%(\mathrm{SW})$ of the total lipid content over all blocks, days, and diets. The pattern of variation in triglyceride content between morphs was very similar to

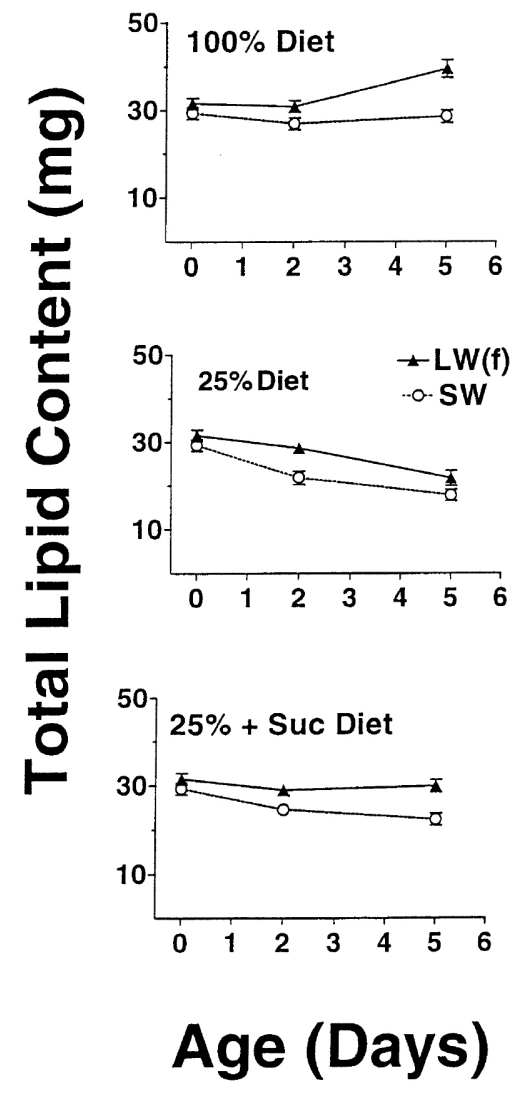

the pattern of variation in total lipid content, while the magnitude of differences between the morphs in triglyceride content was slightly greater than that of total lipid (Figure 3). Newly molted (day 0) LW(f) and SW females did not differ in triglyceride content $\left[F_{(1,52)}\right.$ $=0.49, P=0.49$; Figure 3]. However, mass-adjusted triglyceride content was significantly higher in the $\mathrm{LW}(\mathrm{f})$ than in the SW morph on both day $2\left[F_{(1,147)}=8.0, P=\right.$ $0.005]$ and day $5\left[F_{(1,141)}=11.1, P=0.000\right]$. No significant morph $\times$ diet interactions were observed $(P>0.3$ in both ANCOVAs). When compared on each of the three diets, triglyceride content was significantly higher in the $\mathrm{LW}(\mathrm{f})$ vs. the SW morph on each day on each diet [day 2: $100 \%$ diet, $F_{(1,44)}=47.2, P=0.000 ; 25 \%$ diet, $F_{(1}$, ${ }_{41)}=51.1, P=0.000 ; 25 \%+$ sucrose diet, $F_{(1,48)}=12.5$, $\stackrel{4}{P}=0.000$; Day 5: $100 \% \operatorname{diet} F_{(1,40)}=22.0, \stackrel{P}{P}=0.000$; $25 \%$ diet, $F_{(1,43)}=18.1, P=0.009 ; 25 \%+$ sucrose diet, $\left.F_{(1,44)}=17.4, P=0.000\right]$. The percent elevation in triglyceride content in the $\mathrm{LW}(\mathrm{f})$ vs. the $\mathrm{SW}$ morph was of large magnitude by day 5 of adulthood $(33 \%, 30 \%$, and $39 \%$ on the $100 \%, 25 \%$, and $25 \%+$ sucrose diets, respectively).

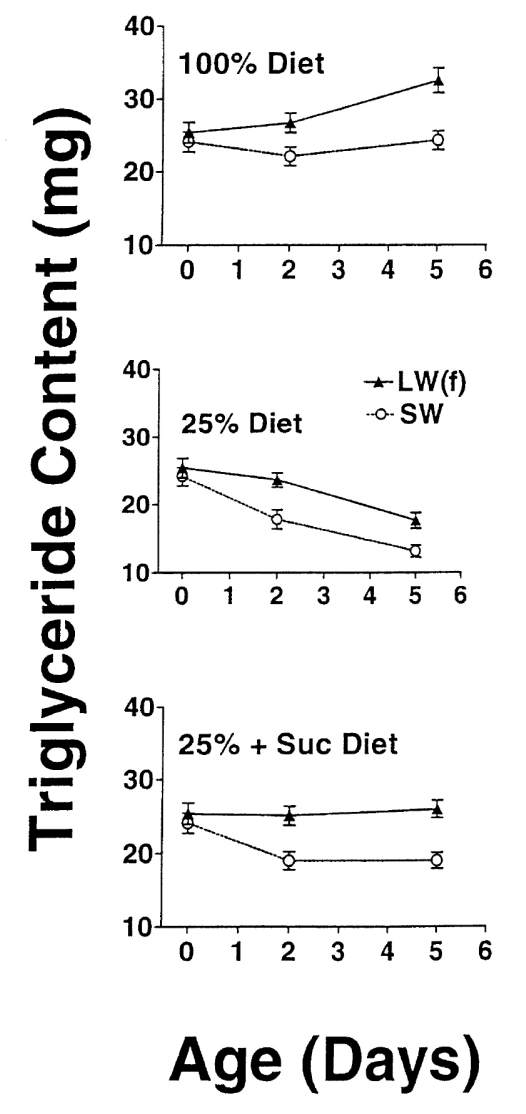

Figure 3. Mean $\pm(S E M)$ total lipid content (left panels) or triglyceride content (right panels) in the flight capable [LW(f)] and flightless SW morphs of G. firmus fed one of three different diets during adulthood. Days refer to days of adulthood. Values are least squares means adjusted for variation in lean body mass by ANCOVA (see Section 2). Adjusted means are averages over the three blocks (no interactions involving block were observed in the ANCOVAs). See Section 2 for explanation of diets and Table 2 for means of individual blocks averaged over days 2 and 5 of adulthood. Sample sizes ranged from 23-28 for each morph on each day on each diet. Note the higher mass-adjusted lipid and triglyceride levels in the LW(f) vs. SW morph on day 5 on all diets, and the equivalent values in the morphs on the day of molt to adulthood (day 0). 


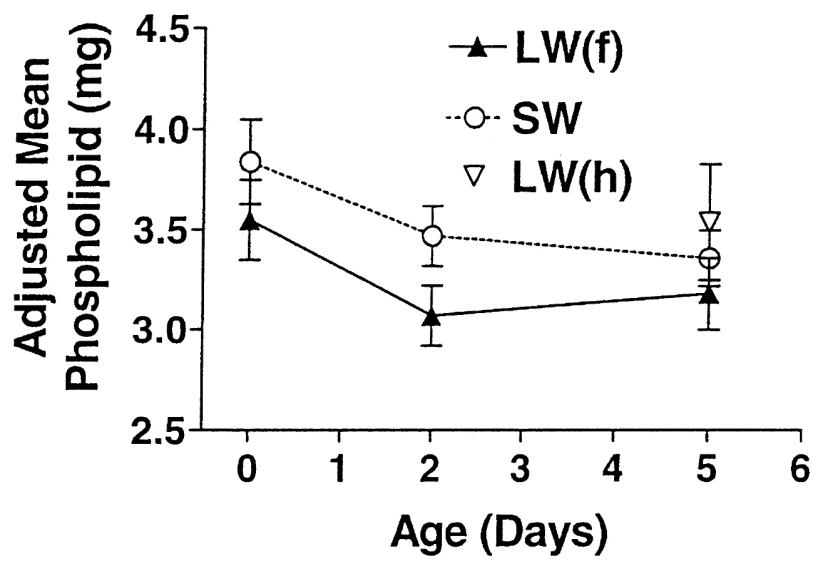

Figure 4. Mean $\pm(S E M)$ phospholipid content in the flight capable [LW(f)] and flightless SW morphs of G. firmus during adulthood. Values are least squares means adjusted for variation in lean body mass by ANCOVA (see Section 2). Adjusted means are averages over the three blocks and three diets (no interactions involving block, diet were observed in the ANCOVAs). Sample sizes ranged from 21-24, and 44-60, for each morph on day 0 and days $2-5$, respectively.

Although triglyceride content differed between LW(f) and SW morphs to a similar degree on each of the three diets (i.e. no significant morph $\times$ diet interactions were observed), temporal patterns of change in this reserve differed between morphs on different diets. On the $100 \%$ diet, the higher triglyceride content in LW(f) vs. SW females was due to an increase in triglyceride content from day 0 to day 5 for the $\operatorname{LW}(\mathrm{f}) \operatorname{morph}\left(F_{(1,47)}=11.7, P=0.001\right.$; Figure 3$)$, coupled with no change in triglyceride content between these two ages for the SW morph $\left(F_{(1,55)}=0.13 ; P\right.$ $=0.72$ ). This situation was reversed on the high-carbohydrate $(25 \%+$ sucrose $)$ diet. Triglyceride content did not change between days 0 and 5 for the $\operatorname{LW}(\mathrm{f})$ morph $\left(F_{(1}\right.$, $\left.{ }_{51}=0.16 ; P=0.68\right)$, but dropped significantly during this time in the SW morph $\left(F_{(1,54}\right)=8.2 ; P=0.006$; Figure 2). On the low nutrient $(25 \%)$ diet, both morphs exhibited a significant reduction in triglyceride content between days 0 and $5\left[\mathrm{LW}(\mathrm{f}): F_{(1,50)}=16.4, P=0.002\right.$; SW: $F_{(1,54)}=39.3$, $P=0.0000]$, although the magnitude of reduction was greater in the SW morph (Figure 3).

Phospholipid accounted for approximately 17\% [LW(f)] or $20 \%(\mathrm{SW})$ of the total lipid content in G. firmus, over all days, diets and blocks. In contrast to the substantially elevated triglyceride content of the LW(f) morph, phospholipid content was moderately higher in the SW vs. the LW(f) morph over all days of adulthood (Figure 4; $\left.F_{(1,255)}=5.36, P=0.02\right)$. Phospholipid content did not differ among diets or blocks ( $P>0.3$ ANCOVA), and exhibited no significant morph $\times$ diet interaction on any day $(P>0.5$ on each day). In addition to having a greater phospholipid content, the SW morph also had a significantly greater proportion of its total lipid due to phospholipid than the $\mathrm{LW}(\mathrm{f})$ morph on days 2 and 5 [ANCOVA of phospholipid content with total lipid as covariate: $\left.F_{(1,206)}=7.92, P=0.005\right]$, but not on the first day of adulthood [ANCOVA: $F_{(1,47)}=1.32, P=0.25$ ]. Phospholipid comprised about $17 \%$ more of the total lipid content of the SW morph compared with the LW(f) morph averaged over all blocks, days and diets.

Soluble carbohydrate content of morphs of G. firmus was more than an order of magnitude lower than triglyceride content (1.2-0.4 mg per morph in a particular, block, age and diet; Figure 5). Morphs did not differ in soluble carbohydrate at the adult molt $\left[F_{(1,58)}=2.58, P\right.$ $=0.11]$. However, the $\mathrm{LW}(\mathrm{f})$ had significantly more carbohydrate than the SW morph on days 2 and 5 of adulthood on the $100 \%$ diet $\left[F_{(1,111)}=53.0, P=0.000\right]$, and on the $25 \%$ diet $\left[F_{(1,112)}=60.9, P=0.000\right]$, but not on the high carbohydrate diet $(25 \%+$ sucrose $)\left[F_{(1,113)}=1.61, P\right.$ $=0.21]$. No significant interactions between morph and diet were observed in any of these tests. On each diet in each morph there was a $40-60 \%$ reduction in total carbohydrate content during the first five days of adulthood $(P<0.001$ in each of six $t$-tests comparing days 0 and 5 of adulthood). Despite these substantial relative differences in soluble carbohydrate content between morphs and days of adulthood, absolute differences were slight, amounting to less than $1 \mathrm{mg}$ ( $<1 \%$ lean body mass).

\subsection{Genetic differences between $L W(f)$ and SW morphs}

Highly-significant genetic differences were observed between LW(f)-selected and SW-selected females with respect to both total lipid and triglyceride content (Table 2). Mean lipid content on days 2 and 5 of adulthood was nearly always significantly higher in LW(f)-selected females than SW-selected females of the same block raised on the same diet $(P<0.05$ in seven of nine $t$-tests; $P=0.06$ 0.08 in the other two $t$-tests; Table 2). Similarly, triglyceride content was significantly higher in the $\mathrm{LW}(\mathrm{f})$ vs. the SW morph of the same block, in eight of nine comparisons ( Table 2). Finally, paired $t$-tests documented that grand mean total lipid and triglyceride were each significantly higher in LW(f)-selected vs. SW-selected females on each of the three diets $(P<0.05$ in each of six paired $t$ tests; Table 2). Similar results were obtained in paired $t$ tests comparing total lipid and triglyceride contents between $\mathrm{LW}(\mathrm{f})$ and SW morphs on either day 2 or day 5 of adulthood (data pooled across diets; results not shown).

In contrast to the substantial genetic differences in total lipid and triglyceride between $\mathrm{LW}(\mathrm{f})$ and SW morphs, we found no strong evidence for genetic differences in soluble carbohydrate or phospholipid between morphs. Total carbohydrate was significantly higher in the LW(f) morph than in the SW morph in six of nine comparisons of morphs from the same block and diet. However, none of three paired $t$-tests of morph means was close to being statistically sig- 
nificant $(P>0.1$ in each case; Table 2$)$. With respect to phospholipid, only one of nine comparisons between LW(f) and SW morphs from the same block and diettreatment was significant $(t$-test, $P<0.025)$, and none of the paired $t$-tests of morph means was significant $(P$ $>0.1$ in each of three paired $t$-tests). By contrast, the higher proportion of total lipid due to phospholipid in the $\mathrm{SW}$ vs. the $\mathrm{LW}(\mathrm{f})$ morph had a significant genetic component on the $100 \%$ diet [paired $t$-test: $t_{(2)}=7.55$, $P<0.01]$, was marginally-significant on the $25 \%+$ sucrose diet $\left[t_{(2)}=3.29, P=0.08\right]$, and was not significant on the $25 \%$ diet $\left[t_{(2)}=1.43, P=0.29\right]$.

\subsection{Phenotypic differences between morphs in lipid and car- bohydrate during the last nymphal stadium}

Because of substantially reduced juvenile survivorship and the low number of LW(f) adults produced on the $25 \%$ diet, lipid and carbohydrate contents were not measured on this diet. In contrast to the large differences in lipid reserves between the adult morphs, only minor differences were observed between morphs during the last nymphal stadium (Figure 6). On the standard $100 \%$ diet, the $L W(f)$ morph did not differ from the SW morph in total lipid on day 5 of the 13-day last stadium [ANCOVA: $F_{(1,58)}=0.001, P=0.98$ ], but had a slightly higher lipid content than the SW morph on day $8\left[F_{(1,39)}=4.39, P=0.04\right.$; Figure 6]. On the 25+sucrose diet, $\mathrm{LW}(\mathrm{f})$ and SW morphs did not differ significantly on either day $8\left[F_{(1,30)}=0.54, P=0.8\right]$, or on day $5\left[F_{(1,}\right.$ $\left.{ }_{30)}=3.3, P=0.08\right]$ of the last nymphal stadium. With respect to soluble carbohydrate, no significant differences were observed between the morphs on any day or diet $(P>0.4$ for all ANCOVAs, except on day 5 on the $25 \%+$ sucrose diet, where $P=0.08$ ).

\subsection{Differences between the two flightless morphs in energy reserves}

Greater than $90 \%$ of cases of flight muscle histolysis [i.e. production of $L W(h)$ females from $L W(f)$ females] occurred after day 2 of adulthood. Therefore, comparisons of reserves between the $\mathrm{LW}(\mathrm{h})$ morph and the other two morphs of G. firmus were only conducted for the day-5 samples (Table 3). On the $100 \%$ diet, the flightless LW(h) and SW morphs had very similar total lipid, triglyceride and soluble carbohydrate, and both flightless morphs differed to a similar degree from the flight-capable LW(f) in each of these compounds. However, on the $25 \%$ diet and $25 \%+$ sucrose diets, energy reserves in the $\mathrm{LW}(\mathrm{h})$ morph were intermediate between, and did not differ significantly from those of either the LW(f) or SW morphs. By contrast, reserves differed significantly or nearly significantly between the LW(f) and SW morphs in five of six comparisons (ANCOVA, $P<$ 0.05 in three of six tests; $P=0.06$ in two of six tests).
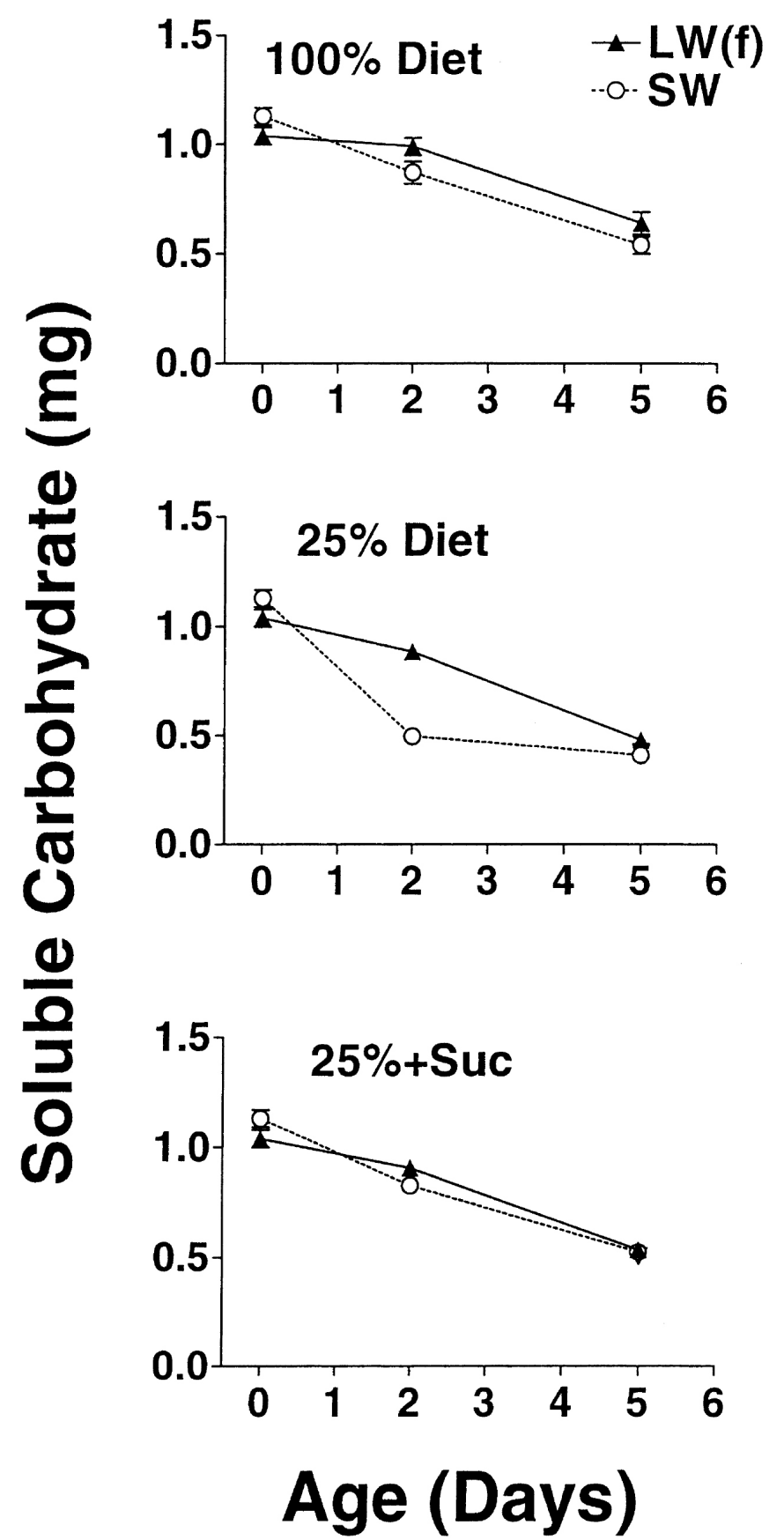

Figure 5. Mean $\pm(\mathrm{SEM})$ soluble carbohydrate (sugars+glycogen) in the flight capable [LW(f)] and flightless SW morphs of G. firmus fed one of three different diets during adulthood. Days refer to days of adulthood. Values are least squares means adjusted for variation in lean body mass by ANCOVA (see Section 2). Adjusted means are averages over the three blocks (no interactions involving block were observed in the ANCOVAs). See Section 2 for explanation of diets and Table 2 for means from individual blocks averaged over days 2 and 5 of adulthood. Sample sizes ranged from 23-28 for each morph on each day on each diet. Note the minor differences between morphs in carbohydrate content compared with differences in triglyceride content ( Figure 3), and the low absolute values of carbohydrates ( $<5 \%$ of triglyceride mass). 


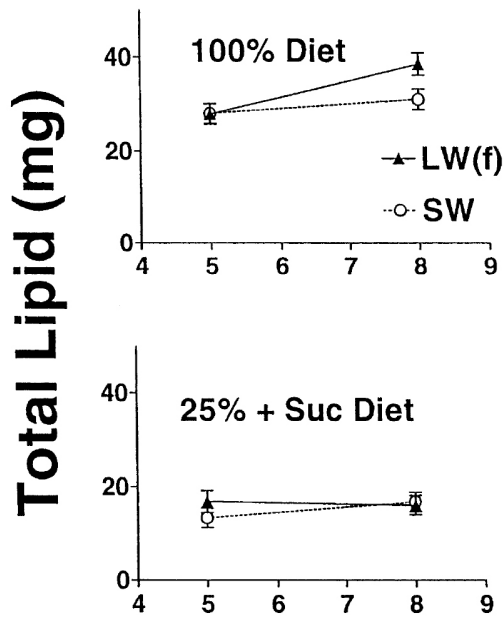

Age (days)

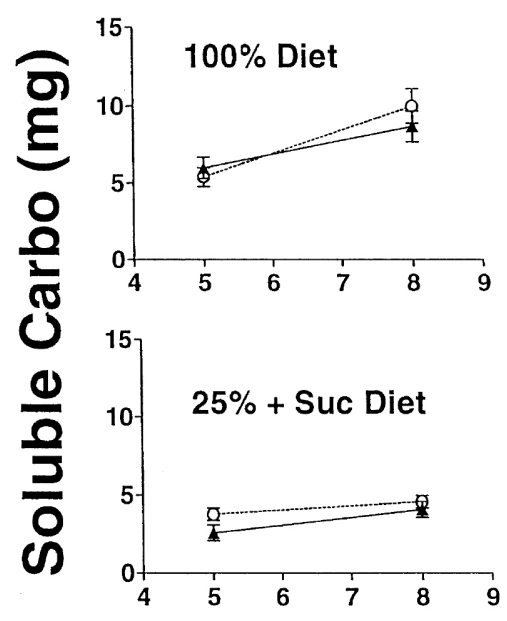

Age (days)

Figure 6. Mean ( \pm SEM) total lipid or total soluble carbohydrate content in nascent LW(f) or SW morphs of G. firmus. Means were adjusted for variation in lean body mass by ANCOVA (see Section 2) and are the average of values obtained in two blocks (Blocks 1 and 3; crickets from block 2 were not assayed). Age refers to the day of the 13-day last stadium. Sample sizes ranged from 15-26 on each day and diet, for each compound studied.

Table 3. Energy reserves in the flight-capable [LW(f)] morph and two flightless morphs [LW(h) and SW] of G. firmus on day 5 of adulthood

\begin{tabular}{|c|c|c|c|c|c|}
\hline \multirow[t]{2}{*}{ Diet } & \multirow[t]{2}{*}{ Compound } & \multicolumn{3}{|c|}{ Morph } & \multirow{2}{*}{$\begin{array}{l}\text { Results } \\
\text { of } t \text {-tests }\end{array}$} \\
\hline & & $\operatorname{LW}(\mathrm{f})$ & LW(h) & SW & \\
\hline \multirow[t]{3}{*}{$100 \%$} & Lipid & $\begin{array}{l}37.8 \pm 1.8 \\
(24)^{\mathrm{b}}\end{array}$ & $\begin{array}{l}26.9 \pm 2.9 \\
(10)\end{array}$ & $\begin{array}{l}27.4 \pm 1.4 \\
(31)\end{array}$ & $\begin{array}{l}* * *,{ }^{* * *}, \\
\text { n.s. }\end{array}$ \\
\hline & Trigly & $33.4 \pm 1.4$ & $23.8 \pm 2.4$ & $25.0 \pm 1.2$ & $* * *, * * *$, \\
\hline & Carbo & $0.64 \pm 0.02$ & $0.55 \pm 0.03$ & $0.58 \pm 0.02$ & $*, * *$ \\
\hline \multirow[t]{3}{*}{$25 \%+S$} & 5 Lipid & $\begin{array}{l}30.0 \pm 1.4 \\
(27)\end{array}$ & $\begin{array}{l}26.2 \pm 2.8 \\
(12)\end{array}$ & $\begin{array}{l}22.5 \pm 1.4 \\
(27)\end{array}$ & $\begin{array}{l}* * * \text {, n.s., } \\
\text { n.s. }\end{array}$ \\
\hline & Trygly & $\begin{array}{l}25.8 \pm 1.2 \\
(24)\end{array}$ & $\begin{array}{l}22.2 \pm 2.3 \\
(8)\end{array}$ & $\begin{array}{l}18.7 \pm 1.1 \\
(27)\end{array}$ & $\begin{array}{l}* * *, \text { n.s., } \\
\text { n.s. }\end{array}$ \\
\hline & Carbo & $\begin{array}{l}0.52 \pm 0.02 \\
(28)\end{array}$ & $\begin{array}{l}0.51 \pm 0.02 \\
(12)\end{array}$ & $\begin{array}{l}0.53 \pm 0.02 \\
(30)\end{array}$ & $\begin{array}{l}\text { n.s., n.s., } \\
\text { n.s. }\end{array}$ \\
\hline \multirow[t]{3}{*}{$25 \%$} & Lipid & $\begin{array}{l}21.9 \pm 1.7 \\
(27)\end{array}$ & $\begin{array}{l}18.3 \pm 1.8 \\
(16)\end{array}$ & $\begin{array}{l}17.9 \pm 1.3 \\
(31)\end{array}$ & $\begin{array}{l}P=0.06, \\
\text { n.s., n.s. }\end{array}$ \\
\hline & Trygly & $\begin{array}{l}16.5 \pm 1.4 \\
(22)\end{array}$ & $\begin{array}{l}15.7 \pm 1.7 \\
(13)\end{array}$ & $\begin{array}{l}13.1 \pm 1.1 \\
(27)\end{array}$ & $\begin{array}{l}P=0.06 \\
\text { n.s., n.s. }\end{array}$ \\
\hline & Carbo & $\begin{array}{l}0.47 \pm 02 \\
(28)\end{array}$ & $\begin{array}{l}0.42 \pm 0.03 \\
(16)\end{array}$ & $\begin{array}{l}0.41 \pm 0.02 \\
(32)\end{array}$ & $\begin{array}{l}\text { *, n.s., } \\
\text { n.s. }\end{array}$ \\
\hline \multicolumn{6}{|c|}{$\begin{array}{l}\text { a Results of } t \text {-tests comparing, respectively, LW(f) vs. SW, } \\
\text { LW(f) vs. } \mathrm{LW}(\mathrm{h}) \text { and } \mathrm{LW}(\mathrm{h}) \text { vs. SW. Since these tests were } \\
\text { all a priori planned contrasts, significance levels were not ad- } \\
\text { justed for multiple comparisons of the same data; }{ }^{*}=P< \\
0.05,{ }^{* *}=P<0.025,{ }^{* * *}=P<0.005 \text {. }\end{array}$} \\
\hline
\end{tabular}

\subsection{Phenotypic correlations}

Partial correlations between the various chemical components of LW(f) and SW adults of G. firmus are given in Table 4 . These correlations were obtained with lean dry body mass held constant (see Section 2). Highmoderate positive correlations were observed among total lipid, triglyceride and soluble carbohydrate in both

Table 4. Partial correlations between various chemical components in morphs of G. firmus (partial correlations estimated with lean dry mass held constant)

\begin{tabular}{|c|c|c|c|c|c|}
\hline & Lipid & Trigly & Phospho & Carbo & Water \\
\hline \multicolumn{6}{|c|}{$L W(f) M_{o r p h}^{\mathrm{a}}$} \\
\hline Lipid & - & & & & \\
\hline Trigly & $0.91^{* *}$ & - & & & \\
\hline Phospho & $0.33^{* *}$ & $0.26^{*}$ & - & & \\
\hline Carbo & $0.42^{* *}$ & $0.42^{* *}$ & $0.15-$ & & \\
\hline Water & 0.01 & 0.00 & 0.12 & -0.13 & - \\
\hline \multicolumn{6}{|c|}{ SW Morph ${ }^{\mathrm{a}}$} \\
\hline Lipid & - & & & & \\
\hline Trigly & $0.93^{* *}$ & - & & & \\
\hline Phospho & 0.11 & -0.01 & - & & \\
\hline Carbo & $0.48^{* *}$ & $0.47^{* *}$ & 0.12 & - & \\
\hline Water & $-0.26^{*}$ & $-0.25^{*}$ & 0.07 & -0.14 & - \\
\hline
\end{tabular}

${ }^{\mathrm{a}} \mathrm{LW}(\mathrm{f})=$ long-winged morph that is capable of flight; SW = shortwinged, obligately flightless morph; $n=121$ LW(f) females and 137 SW females. Correlations were estimated on samples pooled across days 0,2 , and 5 of adulthood and the three diets. Significance levels (derived from Table Y of Sokal and Rohlf (1969) for correlations among four independent variables): ${ }^{* *}=P<0.01,{ }^{*}=P<0.05$; correlations not followed by an asterisk are not significant $P>0.1$. 
the LW(f) and SW morphs. Correlations that were positive in one morph but not in the other were found between phospholipid and total lipid or triglyceride [positive in LW(f), non-significant in SW], and water content and total lipid or triglyceride [negative in SW and nonsignificant in LW(f)]. Similar correlations were observed when the three diets were tested separately, or when the morphs [with or without the LW(h) morph] were pooled. Because of the relatively small sample size $(n=38)$ correlations were not tested on LW(h) individuals separately. The only partial correlation that could be computed for juveniles was that between total carbohydrate and total lipid, which was not significant $(r=$ $0.185, n=59 ; P>0.05)$.

\section{Discussion}

4.1. Genetic differences between morphs in triglyceride reserves: relevance to the trade-off between flight-capability and early reproduction

The most important finding of the present study was the substantially elevated triglyceride content of the flight-capable $[\mathrm{LW}(\mathrm{f})]$ morph vs. the flightless (SW) morph of G. firmus. This difference had a significant genetic component, occurred on each of the three diets studied, and was of large magnitude [30-38\% elevation in triglyceride content in LW(f) vs. SW females on day 5 on each diet]. This result is consistent with and extends our previous finding that triglyceride content is phenotypically higher in the LW(f) vs. the SW morph of G. firmus on one diet (100\% diet; Zera et al., 1994). Results are also consistent with the elevated lipid levels found in the dispersing phase of several phase-polymorphic insect species (summarized in Zera et al., 1994). The present study is one of the few investigations that has documented genetically-based differences in energy reserves between phenotypes that vary in life history traits (reviewed in Zera and Harshman, 2001). To our knowledge, the present study is the first physiological-genetic study of energy reserves in a complex (e.g. phase, caste, flight) polymorphism in insects.

Both the magnitude and timing of appearance of elevated triglyceride in the flight-capable morph suggest that accumulation of this energy reserve may be a potentially important energetic cost of flight capability that directly reduces ovarian growth during the first week of adulthood in G. firmus. As mentioned previously, triglyceride is the major flight fuel in species of Gryllus (Zera et al., 1999), and in many other insect species, where it often accumulates in large quantities (Beenakkers et al., 1985; Downer, 1985; Candy, 1989). The genetically-based elevation in triglyceride reserves in the LW(f) morph was produced slightly before and during the period of early adulthood when a genetically-based reduction in ovarian growth occurred in that morph relative to the SW morph ( Figure 7). Moreover, recent studies have shown that triglyceride biosynthesis is substantially elevated $(>50 \%)$ in $\mathrm{LW}(\mathrm{f})$ vs. SW G. firmus on day day 5 of adulthood on the 100\% diet (Zhao and Zera, in press). Thus, the decreased ovarian growth of the LW(f) morph may be at least partly caused by the increased allocation of limited internal nutrients to triglyceride production or retention. Results of hormone manipulation experiments in the long-wing monomorphic congener, G. assimilis, are consistent with this hypothesis. A juvenile hormone mimic (methoprene) applied topically to long-winged females of this species both significantly reduced triglyceride levels and significantly increased ovarian growth (Zera et al., 1998). Alternatively, internal nutrients may not be limiting, and the negative relationship between accumulation of triglyceride and ovarian mass (primarily yolk protein) in
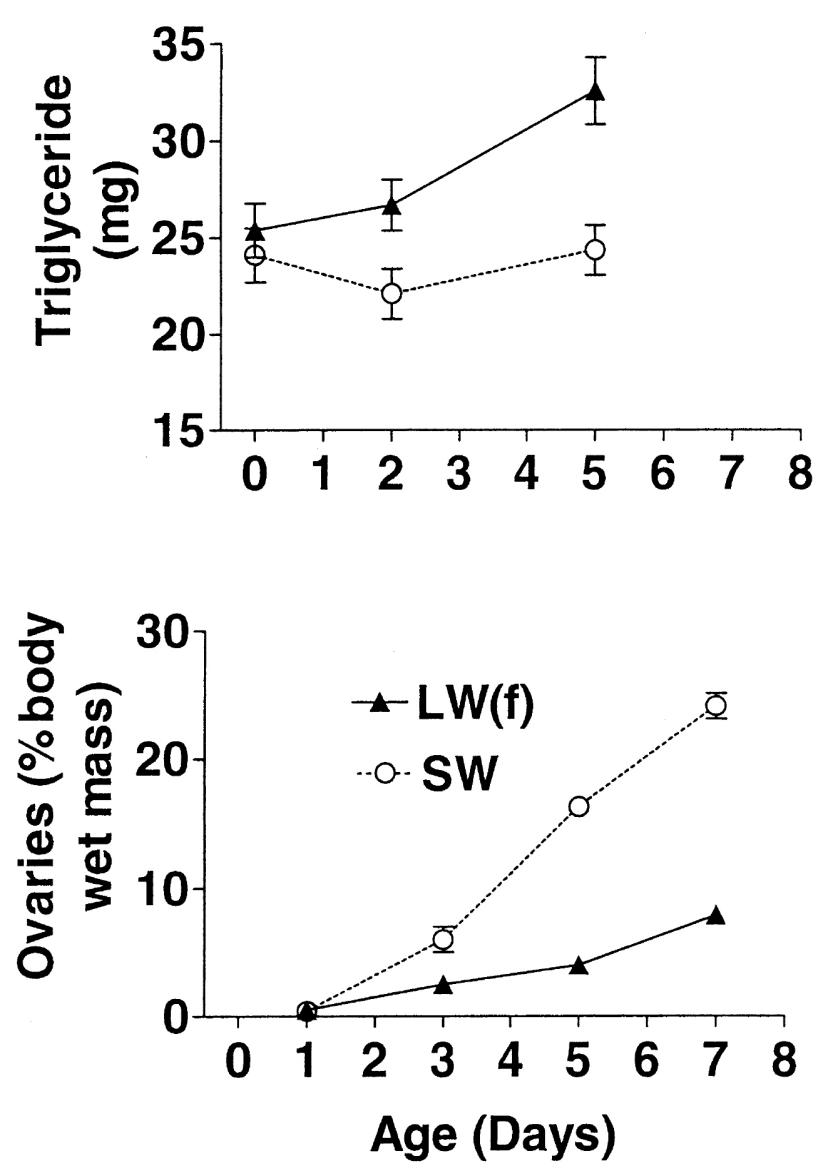

Figure 7. Negative association between mean ( \pm SEM) triglyceride accumulation and mean $( \pm$ SEM) ovarian growth in the flight-capable [LW(f)] and the obligately-flightless SW morphs of G. firmus. Triglyceride data are from the top right panel of Figure 2 (100\% diet; triglyceride data pooled across the 3 blocks). Ovaries (both ovaries) were taken from crickets raised in the same manner as those used for triglyceride estimates $(n$ $=10-15$ per mean). Note that divergence between the morphs in triglyceride content occurs before and during the period of time when morphs diverge in ovarian growth. 
the $\mathrm{LW}(\mathrm{f})$ and SW morphs may result from regulatory or space constraints that preclude the accumulation of both types of compounds. For example, the endocrine requirements for increased lipid biosynthesis may be incompatible with requirements for increased yolk protein biosynthesis. A number of studies in addition to Zera et al. (1998) have documented juvenile hormone mediated trade-offs between lipid accumulation and decreased yolk protein synthesis or ovarian growth (reveiwed in Beenakkers, 1983; Zera et al., 1994) More detailed studies of the interactions between biochemical pathways involved in the yolk protein and lipid biosynthesis will be required to discriminate between these possibilities. Whatever the mechanism by which elevated lipid accumulation leads to reduced ovarian growth, it can have significant fitness consequences. Decreased ovarian growth during the first 1-2 weeks of adulthood in the flight-capable morph of G. firmus (Figure 7) is the major contributor of its overall reduced fecundity relative to the flightless morph ( Roff, 1984), a situation that is similar in many other wing polymorphic species (reviewed in Roff, 1986; Zera and Denno, 1997).

Although triglyceride content was consistently higher in LW(f) vs. SW G. firmus on each of the three diets by the end of the fifth day of adulthood (Figure 2), the processes responsible these morph-specific differences are probably not the same on each diet. For example, on the high-nutrient diet, triglycerides increased significantly between days 0 and 5 in the $L W(f)$ morph but did not change between these two days in the SW morph. This suggests that the increased triglyceride in the LW(f) vs. the SW morph was likely due to increased lipid biosynthesis in the LW(f) morph over the first five days of adulthood. On the other hand, on the low nutrient diet, triglyceride levels decreased in both morphs from day 0 to day 5 , but decreased by a greater degree in the SW morph. This suggests that under low nutrient input, the elevated triglyceride content in the LW(f) vs. SW morph more likely results from a lower overall rate of utilization of lipid reserves in the LW(f) morph, which had accumulated during the nymphal stage. We have recently documented that activities of key enzymes in lipid biosynthesis (e.g. fatty acid synthase, ATP-citrate lyase, glucose-6-phosphate dehydrogenase), and the in vivo incorporation of radiolabelled acetate into total lipid are significantly higher in LW(f) vs. SW females on day 5 of adulthood on the $100 \%$ diet (Zhao and Zera, in press). Moreover, the activities of these enzymes increased considerably from day 0 of adulthood where they did not differ significantly between morphs. These results are consistent with the idea that the elevated triglyceride level in the $L W(f)$ vs. the SW morph on the high-nutrient diet is due to a greater increase in lipid biosynthesis in the LW(f) morph.

An alternate explanation for the elevated triglyceride in the LW(f) vs. SW morph of G. firmus is that the LW(f) morph acquires a greater quantity of lipid from the diet. However, this cannot be the case since we have recently documented that total lipid intake from the diet (due to consumption and assimilation) is not greater in the LW(f) vs. the SW morph (Zera and Brink, 2000; Rooneem and Zera, unpublished data). This is the only case of which we are aware where differential assimilation and consumption can be eliminated as a potential cause of variation between life history phenotypes in the concentration of an energy reserve. A number of studies have suggested that differences in chemical constituents between species or genetic stocks that vary in life histories have arisen by internal trade-offs (e.g. Djawdan et al., 1996). However, these inferences are problematic since investigators lack information on nutrient consumption and assimilation necessary to eliminate differential intake of nutrients as a possible cause of variation in chemical constituents (discussed in more detail in Zera et al., 1998; Zera and Brink, 2000; Zera and Harshman, 2001).

\subsection{Differences in phospholipid and carbohydrate between adult morphs}

In contrast to its lower triglyceride content, the SW morph had a significantly higher amount of phospholipid than the LW(f) morph over all days (Figure 4). Furthermore, proportion of total lipid due to phospholipid on days 2 and 5 (but not on the day of emergence to adulthood) was higher in SW than in LW(f) females ( Section 3). Thus, the LW(f) and SW morphs diverged during the first five days of adulthood in the relative proportion of total lipid allocated to phospholipid (higher in SW) vs. triglyceride [higher in LW(f)], as well as in the absolute amounts of these compounds. The greater accumulation of phospholipid at the expense of triglyceride in the SW morph, and vice versa in the $\mathrm{LW}(\mathrm{f})$ morph, could result from any number of processes, such as a greater proportion of total lipid biosynthesis being directed to phospholipid production or a greater proportion of lipid catabolism coming from triglyceride in the SW vs. the LW(f) morph. Recent radiotracer studies indicate that differential biosynthesis of triglyceride and phospholipid in the LW(f) and SW morphs at least partially explains these observations. On each of the three diets employed in the present study, but especially on the $25 \%$ diet, triglyceride biosynthesis was higher, but phospholipid biosynthesis was lower, in LW(f) vs. SW female G. firmus (Zhao and Zera, in press).

From an energetics perspective, differences in soluble carbohydrate (sugars and glycogen) between adult morphs of G. firmus appear to be less important in the trade-off between flight capability and reproduction than differences in triglyceride. Mass of total carbohydrate was more than an order of magnitude lower than the mass of triglyceride, and differences between the morphs were minimal, amounting to less than one-half $\mathrm{mg}$ of this re- 
serve (Figure 5). Furthermore, no genetic differences were observed between the morphs in carbohydarate content. Only small differences in carbohydrate content between morphs of G. firmus also were observed in the previous study of Zera et al. (1994) [note: as mentioned previously (Zera et al., 1999), values on the $x$-axis of Figure 3 of Zera et al. (1994) should be ten-fold lower than presented; i.e. carbohydrates are 10-fold lower than presented in that figure]. Finally, a moderately strong positive phenotypic correlation was observed between triglyceride and soluble carbohydrate in both morphs ( Table 4). This suggests that metabolic processes responsible for the accumulation of triglyceride and carbohydrate in G. firmus may be co-ordinated to produce elevated levels of all energy reserves in the LW(f) morph.

\subsection{Differences in reserves between nymphal morphs and the two flightless morphs}

In contrast to the large and functionally important differences in lipid and triglyceride content between adult morphs, only minor differences were observed in lipid content, and no differences were observed in carbohydrate content, between nascent morphs during the last nymphal stadium (Figure 6). Furthermore, differences that were observed in lipid content, were eliminated by the first day of adulthood. Thus, there is no evidence in G. firmus that the higher lipid reserves of LW(f) adult females, which may constitute an important energetic cost of flight capability, are produced during the nymphal stage. These results further support the hypothesis that the negative correlation between flight fuel accumulation and ovarian growth in adult G. firmus (Figure 7), may result from a direct negative interaction between pathways involved in lipid and yolk protein biosynthesis during adulthood. In contrast to the results for G. firmus, life history studies in a few other insects have documented differential accumulation of lipid reserves in the juvenile stage by genotypes that differ in life history traits (Chippendale et al., 1996; reviewed in Zera and Harshman, 2001).

G. firmus exhibits the two common types of flightlessness found in insects (Zera and Denno, 1997). The SW morph has both reduced wings and reduced flight muscles, produced by blockage of growth of these organs in nymphs, while the LW(h) morph has fully-developed wings, but reduced flight muscles, produced by muscle histolysis during adulthood. The extent to which these flightless morphs differ from each other and the flightcapable morph in physiological and reproductive traits will have a strong effect on which mode of flightlessness is favored by natural selection ( Zera et al., 1997). In our previous study of energy reserves ( Zera et al., 1994), we did not distinguish between $\operatorname{LW}(\mathrm{f})$ and $L W(\mathrm{~h})$ morphs, and measures for the ' $\mathrm{LW}^{\prime}$ ' morph are a composite of these two morphs. In the present study, on the $100 \%$ diet, both flightless morphs differed from the flight capable LW(f) morph to a similar degree in total lipid, triglyceride and soluble carbohydrate ( Table 3). On the other two diets, the LW(h) and SW morphs also differed in the same direction from the LW(f) morph with respect to total lipid, triglyceride, and carbohydrate, although the differences were not statistically significant between the $\mathrm{LW}(\mathrm{f})$ and $\mathrm{LW}(\mathrm{h})$ morphs. In previous studies, the two flightless morphs were similar to each other and both differed to a similar extent from the LW(f) morph in ovarian growth ( Zera et al., 1997; Zera and Bottsford, 2001), juvenile hormone and ecdysteroid titers ( Zera and Zera) enzyme activities and respiration rates of flight muscles ( Zera and Bottsford, 2001; Zera and Cisper, 2001), and various indices of nutrient assimilation and conversion (Zera and Brink, 2000). These data collectively indicate that the two types of flightless morphs, that are produced by very different developmental mechanisms in different developmental stages, are remarkably similar in a diverse set of physiological characteristics.

\subsection{Summary and prospectus}

We have quantified robust, genetically-based differences in triglyceride content of large magnitude between the LW(f) and SW morphs of G. firmus on all diets and between the LW(f) and the flightless LW(h) morph of this species on the $100 \%$ diet. The strong negative association between triglyceride and ovarian mass (Figure 7) indicates that increased triglyceride accumulation in the LW(f) morph may be an important component of the negative interaction between flight capability and early fecundity in G. firmus. These data have allowed us to formulate and test biochemical hypotheses about the specific aspects of intermediary metabolism that have been altered in G. firmus leading to specializations for flight vs. reproduction (Zhao and Zera, in press).

The present study illustrates the utility of wing polymorphism as an experimental model to investigate the physiological-genetic underpinnings of life history variation. Even though our genetic tests had very low statistical power (i.e. all paired $t$-tests had only two degrees-of-freedom), we were able to document genetically-based differences between the morphs in various energy reserves. This was due to the very large differences in these reserves between the flight-capable $\mathrm{LW}(\mathrm{f})$ and flightless SW morphs (Table 3). The large magnitude of these differences is typical of the degree of variation between morphs for other physiological traits related to flight or reproduction (see above references). Differences of this magnitude make wing polymorphism one of the most powerful experimental models for identifying the underlying physiological, biochemical and molecular bases of life history evolution ( Zera and Harshman, 2001). 


\section{Acknowledgments}

This study was supported by grant IBN-9808249 from the National Science Foundation. A. Larsen was supported by a Research Experience for Undergraduates supplement to the above grant.

\section{References}

Beenakkers, A. T. M., 1983. Regulation of lipid metabolism. In: Downer, G. H., and Laufer, H. (Eds.), Endocrinology of Insects, vol 1. Alan R. Liss, New York, pp. 441-450.

Beenakkers, A. T. M., Van Der Horst, D. J., and Van Marrewijk, W. J. A., 1985. Biochemical processes directed to flight muscle metabolism. In: Kerkut, G. A., and Gilbert, L. I. (Eds.), Comprehensive Insect Physiology, Biochemistry, and Pharmacology, vol. 10. Pergamon Press, Oxford, pp. 451-486.

Candy, D. J., 1989. Utilization of fuels by flight muscles. In: Goldsworthy, G. J., and Wheeler, C. H. (Eds.), Insect Flight. CRC Press, Boca Raton, FL, pp. 305-319.

Chippendale, A. K., Chu, T. J., and Rose, M. R., 1996. Complex trade-offs and the evolution of starvation resistance in Drosophila melanogaster. Evolution 50, pp. 753-766.

Cisper, G., Zera, A. J., and Borst, D. A., 2000. Juvenile hormone titer and morph-specific reproduction in the wing-polymorphic cricket Gryllus firmus. Journal of Insect Physiology 46, pp. 585-596.

Downer, R. G. H., 1985. Lipid metabolism. In: Kerkut, G. A., and Gilbert, L. I. (Eds.), Comprehensive Insect Biochemistry, Physiology, and Pharmacology, vol 10. Pergamon Press, Oxford.

Djawdan, M., Sugiyama, T. T., Schlaeger, L. K., Bradley, T. J., and Rose, M. R., 1996. Metabolic aspects of the trade-off between fecundity and longevity in Drosophila melanogaster. Physiological Zoology 69, pp. 1176-1195.

Fisher, R. A., 1930. The Genetical Theory of Natural Selection. Dover, New York.

Harshman, L. G., and Hoffmann, A. A., 2000. Laboratory selection experiments using Drosophila: what do they tell us?. Trends in Ecology and Evolution 15, pp. 32-36.

Harshman, L. G., and Schmid, G., 1998. Evolution of starvation resistance in Drosophila melanogaster: aspects of metabolism and counter-impact selection. Evolution 52, pp. 1679-1685.

Johnson, G. C., 1969. Migration and Dispersal of Insects by Flight. Methuen, London.

Mole, S., and Zera, A. J., 1993. Differential allocation of resources underlies the dispersal-reproduction trade-off in the wing-dimorphic cricket Gryllus rubens. Oecologia 93, pp. 121-127.

Pianka, E. R., 1981. Resource acquistion and allocation among animals. In: Towsend, C. R., and Calow, P. (Eds), Physiological Ecology. An Evolutionary Approach to Resource Use. Blackwell Sceintific Publications, Oxford, pp. 300-314.

Roff, D. A., 1984. The cost of being able to fly: a study of wing polymorphism in two species of crickets. Oecologia 63, pp. 30-37.

Roff, D. A., 1986. The evolution of wing dimorphism in insects. Evolution 40, pp. 1009-1020.

Rose, M. R., Nusbaum, T. J., and Chippendale, A. K., 1996. Laboratory evolution: the experimental wonderland and the Cheshire Cat Syndrome. In: Rose, M. R., Lauder, G. V. (Eds.), Adaptation. Academic Press, San Deigo, pp. 221-244.

Service, P. M., 1987. Physiological mechanisms of incresed stress resistence in Drosophila melanogaster selected for postponed senescence. Physiological Zoology 60, pp. 321-326.
Tanaka, S., 2001. Effects of supressed oviposition activity and flight muscle histolysis on food consumption and ovarian development in a wing-dimorphic cricket: an explanation for sporadic conclusions related to physiological trade-offs. Journal of Insect Physiology 47, pp. 83-94.

Towsend, C. R., and Calow, P., 1981. Physiological Ecology. An Evolutionary Approach to Resource Use. Blackwell Sceintific Publications, Oxford.

Van Handel, E., 1965. Microseparation of glycogen, sugars, and lipids. Analytical Biochemistry 11, pp. 266-271.

Van Handel, E., 1985. Rapid determination of total lipids in mosquitoes. Amercian Journal of Mosquito Control Association 1, pp. 302-304.

Veazy, J. N., Kay, C. A. R., Walker, T. J., and Whitcomb, W. H., 1976. Seasonal abundance, sex ratio, and macroptery of field crickets in northern Florida. Annals of the Entomological Society of America 69, pp. 374-380.

Zera, A. J., and Bottsford, J., 2001. The endocrine-genetic basis of life-history variation: relationship between the ecdysteroid titer and morph-specific reproduction in the wing-polymorphic cricket, Gryllus firmus. Evolution 55, pp. 538-549.

Zera, A. J., and Brink, T., 2000. Nutrient absorption and utilization by wing and flight muscle morphs of the cricket Gryllus firmus: implications for the trade-off between flight capability and early reproduction. Journal of Insect Physiology 46, pp. 1207-1218.

Zera, A. J., and Cisper, G., 2001. Genetic and diurnal variation in the juvenile hormone titer in a wing-polymorphic cricket: implications for the evolution of life histories and dispersal. Physiological and Biochemical Zoology 74, pp. 293-306.

Zera, A. J., and Denno, R. F., 1997. Physiology and ecology of dispersal polymorphism in insects. Annual Review of Entomology 42, pp. 207-231.

Zera, A. J., Harshman, L. G., 2001. The physiology of life history trade-offs in animals. Annual Review of Ecology and Systematics, in press.

Zera, A. J., and Huang, Y., 1999. Evolutionary endocrinology of juvenile hormone esterase: functional relationship with wing polymorphism in the cricket, Gryllus firmus. Evolution 53, pp. 837-847.

Zera, A. J., Mole, S., and Rokke, K., 1994. Lipid, carbohydrate and nitrogen content of long- and short-winged Gryllus firmus: implications for the physiological cost of flight capability. Journal of Insect Physiology 40, pp. 1037-1044.

Zera, A. J., Potts, J. and Kobus, K., 1998. The physiology of life history trade-offs: experimental analysis of a hormonally-induced life history trade-off in Gryllus assimilis. American Naturalist 152, pp. 7-23.

Zera, A. J., Sall, J., and Grudzinski, K., 1997. Flight-muscle polymorphism in the cricket Gryllus firmus: muscle characteristics and their influence on the evolution of flightlessness. Physiological Zoology 70, pp. 519-529.

Zera, A. J., Sall, J., and Otto, K., 1999. Biochemical aspects of flight and flightlessness in Gryllus: flight fuels, enzyme activities, and electrophoretic profiles of flight muscles from flight-capable and flightless morphs. Journal of Insect Physiology 45, pp. 275-285.

Zhao, Z., and Zera, A. J. Enzymological and radiotracer studies of lipid metabolism in the flight-capable and flightless morphs of the wing-polymorphic cricket, Gryllus firmus. Journal of Insect Physiology, in press. 